\title{
DEPOIMENTOS E SAUDADES
}

\section{Miguel Alberto Bartolomé}

Soy nacido en Misiones, Argentina, tierra fronteriza con la querıda Santa Catarina de Silvio, pero desde 1972 vivo en Mexico Como antropologo conocí a Sílvio en 1971, en Barbados, cuando ambos participabamos en un simposio sobre friccion interetnica en America Latına, que dio origen al que fuera llamado Grupo de Barbados que produjo otras reuniones, obras y documentos Ese fue el comienzo de una colaboracion profesional que no tardo en transformarse en una leal amıstad Sılvio no sólo me abrı las puertas de su casa sino también la de su pais ya que a partır de 1987 fuı invitado como profesor visitante a la Unıversıdade Federal de Santa Catarına, y de allí a la de Rıo, São Paulo, Curıtıba, Bahıa y en los ultımos años a Brasılıa Hemos colaborado en varıos libros y elaborado distıntos documentos, juntos hemos intentado apoyar las causas indígenas en América Latına Hemos compartido churrasquitos, whiskys, playas y amistad El inmenso y amado Brasil es ahora un poco solitarıo para mı

\section{Alicia M Barabas}

Soy una antropologa argentina pero desde 1972 radico en Méxıco, donde soy profesor-ınvestıgador del Instıtuto Nacional de Antropologia e Historia Conozco a Sılvio desde la década de 1970, ya que formo parte del Grupo de Barbados junto con mi colega y esposo Miguel Bartolomé Desde muy pronto nos unieron los intereses profesionales compartıdos, y en especial los referidos a las poblaciones indigenas afectadas por represas, tema del cual Silvio ha sido uno de los investigadores pioneros en America del Sur Nuestra amistad propıcıo mi presencia como Profesora Visitante en la Unuversidade Federal 
de Santa Catarina en varıas oportunıdades, así como invitaciones a otras instituciones academicas, tales como las Unıversidades de Rio de Janeiro, Curıtıba, Bahıa o de São Paulo, tambıen logramos que él nos visitara en Oaxaca, México Hemos asıstıdo juntos a reuniones en Europa y América partıcıpando en obras conjuntas Nos unıó una relación profesıonal y personal, junto a su querıda esposa Alaır Sílvı fue un hombre generoso y un antropólogo pionero, su amistad y su obra serán inolvidables

\section{João Baptista Borges Pereira}

Sou professor emento da USP, professor pleno de Pós-Graduação da Unıversıdade Mackenzıe Conhecı Sılvıo, aında em Florıanópolıs, na decada de 60, quando ele era assıstente do professor Osvaldo Cabral Reencontreı-o anos depoıs na então cadeura de Antropologıa, já como doutorando sob orıentação do professor Egon Schaden Quando Schaden se aposentou, no final da decada de 60, assumi, como livre docente, a regência da cátedra, e recebı como herança seus doutorandos, entre os quars estava Sílvio Coelho dos Santos Sílvıo doutorou-se, com louvor, sob minha onentação, no dia 17 de março de 1972, com a tese "Índıos e brancos no Sul do Brasıl - a dramátıca experiêncıa dos Xokleng' Sua banca João Baptısta Borges Pereira, Ruı Galvão de Andrada Coelho, Roberto Cardoso de Olıverra, Luiz Pereira e Egon Schaden

Antes, em 1971, participou da famosa reunião da ABA, coordenada por Egon Schaden e por mum, na ausência de seu Presıdente Manuel Diegues Jr Dessa reunião, paiticıpou juntamente com o Prof Willıam H Croocker, Amadeu Duarte Lana e Gunther Protasıus Frıkel, da $2^{\text {a }}$ sessão, dıa 16/09/71, período da manhã

Sílvio assıstıu pessoalmente a inexplıcável (ou explıcável?) explosão da ABA nessa reunião A entıdade for por ele, quase 20 anos depoıs, resgatada na famosa reunão de Florianopolıs, quando for eleito o seu presidente em 1992, chapa em que fui diretor A ABA, a antropologıa do Brasıl e a nova geração de antropólogos brasuleiros têm essa dívida com o nosso saudoso Sulvio Coelho dos Santos Lembremse disso 


\section{Jesús Ruvalcaba Mercado}

Semblanza Llego temprano al CIESAS y de reojo veo una cara apacible, desconocida concentrada en sus papeles, sun apenas mirar a su alrededor aunque al mismo tiempo trasmite la sensacion de percatarse de todo lo que ocurre no solo en lo alcanzable a su vista sino que, se puede pensar, va mucho mas lejos Es el profesor Sílvı Coehlo dos Santos, profesor visitante apenas llegado de Brasil Aunque solo mclinamos la cabeza a manera de saludo, ninguno de los dos puede imaginar la cordıal amıstad que nos uniría años despues y que luego de revisar sus trabajos se transformaria en mi admiracion por su obra, primero, y por su persona despues Graclas a su ayuda, pude $x$ junto con mi hija Itzel a Florianopolıs durante un semestre sabatico para impartır un semınarıo acerca de campesınos latınoamericanos, que el tuvo el tacto y buen tino de cambiarlo por uno de historia de Mexico que se vıo mas acudıdo de lo esperado Con gran cordıalıdad, mi hıa y yo fumos invitados varias veces a compartir diversos platillos, muchos preparados por él mismo, en reunıones famılıares muy gratas, que además me resultaban verdaderas cátedras de cocına, historı del Brasıl, la colonızacıon europea en Santa Catarına, los problemas indigenas a lo largo y ancho del contınente Nos volvimos a ver por ultıma vez luego de cası diez, en Mexico, en donde tuve la fortuna de poder compartır con el y su esposa Alaur, una comıda mexıcana de la que era aficionado y gran conocedor Fue nuestro últumo encuentro Con todo, nos manteníamos en contacto intercambiando saludos planes y hechos Ası llegó Eduardo, uno de los ultımos estudıantes a quien le dirıgiera la tesis de posgrado acerca de los guaranies, no sin antes conocer su capacıdad de trabajo e intelıgencia, es decır, de pasar la prueba Las asesorias ıban más alla de la relación profesor alumno y, aunque ya afectado del cáncer, se ocupaba y se preocupaba por su bıenestar era a la vez exıgente y cordıal, niguroso y buen guía Por lo mismo, no fue extraño que Sergıo Eduardo se titulara el primero de su generacion y a tıempo a pesar de los problemas del ıdıoma El aliento a los alumnos se traducia en un gran respeto y carnño por el profesor Sí, lo recordamos con gran alegria por la vida, la sonrisa pronta, la palabra de alıento, la palabra sabıa a tıempo En breve, tanto como colega como profesor, Sílvio tenía una generosidad fuera de lo común 
$\mathrm{y}$, como persona, nosotros queremos resaltar su fortaleza, su entereza ante la adversıdad, que nunca lo pudo vencer Hasta pronto, querido profesor

\section{Sergio Eduardo Carrera Quezada}

En visperas de mi primera visita a Florianopolis pai a participar en La V Reunion de Antropologia del Mercosur, el dr Jesus Ruvalcaba me recomendó que al llegar a la UFSC preguntase por el profesor Sílvio Coelho dos Santos No imaginaba que aquel hombre ina a marcar el destuno de mı vıda en tıerras brasıleñas Tiempo despues, cuando regresé a Florianopolıs para realızar la maestria en Antropologia Social, de inmediato me puse en contacto con el, porque desde la vez anterıor supe que era el ındıcado para durigur mı trabajo Desde el unıcıo hubo dos cosas en las que concordamos, lo que incentivó que de una relación alumno-profesor se desarrollara una verdadera amistad el interes por la problematica de las sociedades indígenas y su relación con los Estados Nacionales, y los lazos que mantuvo con el CIESAS y con investıgadores mexicanos, para lo cual la distancia no fue un obstáculo

$\mathrm{Al}$ principio fue difícl convencerlo de que dungiera mi proyecto de maestría, pero mu terquedad y obstinación fue tan grande que luego de leer el proyecto inicial acepto con ciertas condiciones Ası comenzaron las asesonas y la recomendación de lecturas, en sesıones acompañadas de una buena taza de cafe expreso, cargado y sm azucar, como le gustaba tomarlo a él Por cierto, al profesor Sílvio tambien le debo esa costumbre

Despues del segundo semestre, todos, especialmente yo, nos sorprendimos con la noticıa de la enfermedad quc aquejaba a mi tutor Todos entramos en panico menos el mismo Frente a esta situacion, algunos profesores y colegas del programa recomendaban un cambı de asesor, pues creían que la enfermedad ıba a termınar pronto con la salud de Silvio No obstante, desde un principio me opuse Para sorpresa general, debido al gran espiritu de trabajo anımo y compromiso consıgo mismo y con los demás, Silvıo supero la primera etapa critica del cancer Si bien estuvo ausente por algunos meses, yo nunca deje de recibur sus comentarıos 
Sílvıo regresó al NEPI, su centro de operaciones, que junto con el demas personal (Marcia, Katıa, Kaı, Gerusa, y disculpen sı olvido a alguno), recibiamos del profesor consejos para resolver nuestros problemas academicos Y no solo esos, sino que tambien los que aquejan al alma, pues al ver la fortaleza con la que enfrento su enfermedad, cualquier proyecto de investıgación, de si no llego la beca, que si teníamos mucho trabajo, si nos sentımos solos o tristes, hacia que los mismos parecieran algo insignificante y sin sentido

Ya de regreso Mexıco, supe que Sílvıo querıa venır en varıas ocasiones mas siempre estuvo sujeto a lo que le recomendaran los médicos A pesar de los varıos kılómetros que nos separaban, nunca dejamos de comunicarnos Incluso en fechas recientes, recibia correos de el manifestando su interes de asistur al $53^{\circ}$ Congreso Internacional de Americanistas a realizarse en el 2009

No puedo dejar de manifestar mi orgullo por haber sıdo el últımo de los alumnos que el dr Sílvıo Coelho dos Santos asesoro, pues en vida fue uno de los grandes precursores de la antropologia brasıleña Enseñanza fortaleza y amıstad, tres palabras que resumen a esta gran persona Sílvıo aquı y mas alla de la Tierra Sin Males

\section{Flávıo Braune Wuk}

A partır de meados dos anos noventa, quando me preparava para realizar pesquisa de campo entre os Xokleng, parte do doutoramento em Antropologia pela Universidade de Chicago, tive o grande prazer de aproxımar-me do caro e sabıo professor Sulvio Coelho Silvio esteve sempre presente em minha trajetorıa acadêmıca desde então, abrundo camınhos, repartındo informações dados (chegando até a me ceder seus cadernos de campo) e, principalmente mostrando como estabelecer vínculos entre o ngor acadêmıco o ensıno e a responsabı hdade em prontamente assessorar os Xokleng em suas historicas lutas politicas Este artigo é uma singela homenagem a sua trajetoria

\section{Esther Jean Langdon}

Eu tunha conhecımento do prof Sílvıo em 1983 nas preparatıvas de vir a Unıversidade Federal de Santa Catarina como professora visi- 
tante A minha vinda ao Brasil for quase totalmente por acaso Estive com a possıbilıdade de um ano sabátıco da faculdade onde munistreı aulas quando chegou uma carta anunciando o interesse do Programa de Pos-Graduação em Cıências Socıaıs de receber um professor vısıtante De verdade, nunca tınha pensando vir ao Brasıl Munha experıência dos 5 anos na América Latına tunha sıdo nos paises de lingua espanhola, mas como Brasıl faz parte de Amérıca Latına, lugar especial para mım, pensel "por que não?" e acelteı o convite Durante os três meses antes de vir, encontrel poucas pessoas, brasileiras ou norte-americanas que conhecıam Florıanópolıs Tem que lembrar que Florıanópolıs recém tunha entrado no mercado de turısmo, e ainda a cidade tanto quanto a Unıversıdade, foram caracterızadas por um certo provincianısmo e ısolação A frase mais corrente dos brasıleıros que ouvı for 'Não conheço Dizem que esta muita linda, mas não conheço" Nas vesperas da vıagem, encontreı doıs antropólogos que conhecıam a Ilha e ao Sílvı O antıopólogo e ındıgenısta Davıd Prıce falava das belezas da Ilha suas florestas, orquideas e bromelıas Porem, fol Scott Robınson quem expressou sua admiração pelo professor Sílvıo e sua atuação polıtıca na luta dos direitos indıgenas e sua partıcıpação na conferêncıa em Barbados indicando que era já internacionalmente conhecıdo

Logo depoıs da minha chegada, ingresseı na equipe de Sılvıo para partıcıpar numa pesquısa sobre a implantação de I 9 barragens na bacıa do rıo Uruguaı, junto com Neusa Bloemer, Analıse Nacke Marı Jose Reıs, Dennıs Werner, e Paulo Freıre, que havıa recém chegado também A Eletrosul solıcıtou a pesquisa objetıvando um estudo dos impactos socioculturais Resultou que na prımeira excursão de campo (eu com Aneliese e Marıa José) fomos convencidos por uma demonstração do Movimento Sem Terra num local proposta para uma barragem de não realızar a pesquisa para a Eletrosul temendo a manıpulação de nossos dados e consıderando os sentımentos do movimento contra as barragens Lembro bem nosso encontro com o professor Sílvı, então pro-reıtor de Pos-Graduação, para avısar-lhe de nossa decisão Sempre etıca na sua postura, ele observou sobre a grande perda de financiamento para a Unıveısıdade que a nossa decısão implıcou, mas acatou a decısão 
Após de uma breve pesquisa sobre o impacto da barragem entre os Xokleng, não contınueı partıcıpando na equıpe de Sílvı, e partı para o tema especifico de saúde indigena Porém, ao longo dos anos, ele se demonstrou em varıos momentos ser um grande amıgo e colega, sempre me apolando e me aconselhando no âmbito deste novo pals que chegueı a adotar Reconheceu a minha capacıdade e a ımportâncla do meu tema, um tema que estava só iniciando a ter enfoque no Brasıl Me convıdou a falar sobre o tema em debates sobre a questão indigena e me incluıu nas suas publicações Devo ao seu apoıo o fato de ser pesquisadora de CNPq desde 1988 Em suma, devo muito ao professor Sílvio para o êxito de minha permanêncıa no Brasıl Inclusive, devo a possibilidade de adotar este país a ele For ele, como pro reitor, o responsavel pela minha vinda, entre a de vános outros professores E quando meu contrato de professora visitante estava expirando, e me convidaram para realızar um concurso de professor efetıvo, frente a munha indecısão de fıcar e largar a minha posıção nos Estados Unudos Sılvıo fol essencial no seu aconselhamento Sem este, não estarıa aquı hoje, 25 anos depois 